\title{
PEMBENTUKAN EMS (EMERGENCY MEDICAL SYSTEM) SEDERHANA MELALUI 3D (DETECTION, DISPATCH, DELIVERY) DALAM MENINGKATKAN MANAJEMEN PRA- HOSPITAL PASIEN STROKE DI DESA GROGOL WILAYAH KERJA PUSKESMAS CUKIR KABUPATEN JOMBANG
}

\section{Establishment Of Simple Ems (Emergency Medical System) Through 3d (Detection, Dispatch, Delivery) In Improving Stroke Patient Pra-Hospital Management In Work Region Grogol Village Puskesmas Cukir Jombang}

\author{
Anja H. Kholis ${ }^{1}$ \\ ${ }^{1}$ Sekolah Tinggi Ilmu Kesehatan Pemkab Jombang \\ Pendidikan Profesi Ners, Keperawatan Medikal Bedah, STIKes Pemkab Jombang, Jombang, 61411, Indonesia \\ Email: hesniaanja@gmail.com
}

\begin{abstract}
ABSTRAK
Pra-hospital delay adalah penyebab utama keterlambatan pengobatan pada penyakit stroke. Waktu dari onset stroke sampai kunjungan ke rumah sakit merupakan kontributor terbesar terhadap keterlambatan sejak awal stroke akut untuk memulai pengobatan. Akibatnya dapat meningkatkan angka kematian dan kecacatan pasien stroke. Idealnya, manajemen pra hospital dimulai saat pasien atau siapapun pengamat pasien mengenali tanda dan gejala stroke segera menelepon 911, tetapi penilaian cepat dan transportasi yang tersedia masih belum maksimal sehingga saat pasien sampai di RS sudah melewati window periode.

Kader yang ada di Desa Grogol sangat pro aktif dalam mendukung semua kegiatannya, namun belum terpapar tentang deteksi dini F.A.S.T stroke (Detection). Fasilitas yang dimiliki untuk memudahkan transportasi (Delivery) warga ke fasilitas kesehatan terdekat adalah ambulans desa. Hanya saja belum diketahui bagaimana sistem komunikasi antara ambulans desa dan penyedia fasilitas kesehatan terdekat (Dispatch). Sehingga diperlukan adanya rangkaian kegiatan pengaktifan EMS sederhana melalui 3D (Detection, Dispatch, Delivery) dalam meningkatkan manajemen prahospital pasien stroke.
\end{abstract}

Kata kunci : Deteksi dini, F.A.S.T Stroke, EMS sederhana, Transportasi ambulans desa, Pra Hospital, Stroke

\section{ABSTRACT}

Pre-hospital delay is the main cause of late treatment in stroke. The time from stroke onset to hospital visit is the biggest contributor to the delay from the onset of acute stroke to start treatment. The result can increase stroke mortality and disability patients. Ideally, pre-hospital management starts when the patient or any patient observer recognizes stroke signs and symptoms immediately calls 911, but the rapid assessment and available transportation is still not maximal so that when the patient arrives at the hospital, the period window has passed.

Cadres in Grogol Village are very pro active in supporting all of their activities, but have not been exposed to early detection of F.A.S.T stroke (Detection). The facilities owned to facilitate transportation (Delivery) of residents to the nearest health facility are village ambulances. It's just not known how the communication system between the village ambulance and the nearest health facility provider (Dispatch). So we need a series of simple EMS activation activities through 3D (Detection, Dispatch, Delivery) in improving the management of pre-hospital stroke patients.

Keywords: Early detection, F.A.S.T Stroke, simple EMS, village ambulance transportation, Pra Hospital, Stroke

\section{Pendahuluan}

Stroke dapat menyebabkan kematian dan kecacatan baik secara fisik maupun mental. Keluhan pertama pasien stroke sebesar $(95 \%)$ dimulai sejak di luar rumah sakit. Pra hospital delay adalah penyebab utama keterlambatan pengobatan pada penyakit serebrovaskular.
Waktu dari onset stroke sampai kunjungan ke rumah sakit merupakan kontributor terbesar terhadap keterlambatan sejak awal stroke akut untuk memulai pengobatan (Yanagida, Fujimoto, Inoue, \& Suzuki, 2014). Akibatnya dapat meningkatkan angka kematian dan kecacatan pasien stroke. Idealnya, manajemen 
pra-hospital dimulai saat pasien atau siapapun pengamat pasien mengenali tanda dan gejala stroke segera menelepon 911, tetapi penilaian cepat dan transportasi yang tersedia masih belum maksimal sehingga saat pasien sampai di RS sudah melewati window periode (Jauch, French, \& McGeorge, 2016).

Upaya pencegahan primer agar tidak terjadi stroke telah banyak dilakukan dalam rangka menurunkan angka kejadian stroke. American Stroke Association mengembangkan rangkaian fokus pengenalan stroke dan pengaktifan EMS melalui Detection, Dispatch, Delivery untuk pre hospital dan Door, Data, Decision, Drug saat di rumah sakit (Jauch, French, \& McGeorge, 2016). Pendidikan masyarakat tentang gejala stroke dan akses pengaktifan EMS awal adalah komponen penting dari regional manapun untuk mengembangkan manajemen pra-hospital pasien stroke (Jauch, French, \& McGeorge, 2016).

Masyarakat membutuhkan suatu alat yang berguna untuk menilai gejala awal stroke (Detection) yang juga dapat divalidasi oleh tenaga medis. Salah satu tools yang mudah dipahami dan cepat diaplikasikan adalah $F$. A. S. T. (Face drooping, Arm Weakness, Speech difficulty, Time to call 911) (American Heart Association, 2013). Penilaian difokuskan pada ketidaksimetrisan wajah, kelemahan ekstremitas dan kesulitan berbicara. Kader yang ada di Desa Grogol sangat pro aktif dalam mendukung semua kegiatan program Puskesmas Cukir, namun belum terpapar tentang deteksi dini F.A.S.T stroke (Detection).

Fasilitas yang dimiliki untuk memudahkan transportasi (Delivery) warga ke fasilitas kesehatan terdekat adalah ambulans desa. Kabupaten Jombang memberikan fasilitas pelayanan mobil ambulans ini di setiap desa. Hanya saja belum diketahui bagaimana sistem komunikasi antara ambulans desa dan penyedia fasilitas kesehatan terdekat
(Dispatch). Sehingga diperlukan adanya rangkaian kegiatan pengaktifan EMS sederhana melalui 3D (Detection, Dispatch, Delivery) dalam meningkatkan manajemen pre hospital pasien stroke.

\section{Metode}

Metode yang digunakan dalam pengabdian masyarakat ini adalah Focus Group Discussion (FGD) yang berfokus pada pelaporan skrining faktor risiko stroke, tindak lanjutnya, dan mekanisme komunikasi antara kader, tenaga kesehatan setempat, serta supir ambulans desa. Selain itu pada pengabdian masyarakat ini juga dilaksanakan sosialisasi deteksi dini F.A.S.T stroke. Sasaran pengabdian masyarakat adalah kader dan perangkat Desa Grogol, supir ambulans desa, bidan dan perawat desa, serta perawat Puskesmas Cukir.

\section{Hasil}

Kegiatan pengabdian masyarakat ini dilaksanakan pada hari Rabu tanggal 26 September 2018 pukul 15.00 s/d 17.30 WIB di Balai Desa Grogol. Kegiatan ini dihadiri oleh 20 orang, diantaranya perwakilan kader dari masing-masing pos, perangkat Desa Grogol, supir ambulans desa, bidan dan perawat desa, perawat Puskesmas Cukir, serta mahasiswa STIKes Pemkab Jombang. Seluruh peserta mengikuti kegiatan dari awal hingga akhir, hanya beberapa yang datang terlambat.

Berdasarkan hasil FGD didapatkan bahwa bidan dan perawat desa, serta kader di masing-masing pos mengetahui data masyarakat yang memiliki faktor risiko stroke. Faktor risiko stroke (hipertensi, DM, kolesterol, dan obesitas) sudah tercatat di dalam buku laporan milik Bidan desa yang secara berkala dilaporkan ke Puskesmas Cukir. Namun semua itu hanya masih berupa data belum ada tindak lanjut ke masyarakat secara langsung. Beberapa kader menyatakan warga yang sudah terdeteksi hipertensi sudah 
berobat dan ketika ke posyandu sudah membawa obat sendiri.

Selain itu juga mendiskusikan tentang struktur penanggung jawab dan pola komunikasi dan mekanisme EMS sederhana yang sudah ada di masyarakat. Kader di Desa Grogol sudah memiliki jejaring komunikasi berupa grup aplikasi daring, yang bernama "Kader Grogol Nyentrik". Perangkat desa khususnya kepala desa masuk dalam anggota grup tersebut. Semua informasi dan kegiatan dibagikan melalui grup tersebut.

Mekanisme komunikasi tentang anggota masyarakat yang sakit belum tergambar secara jelas. Beberapa kader menjelaskan bahwa sebagian besar warga menunggu pengambil keputusan untuk dilakukan tindak lanjut kepada anggota yang sakit. Berdasarkan keterangan beberapa kader dan kepala desa, masyarakat sudah memiliki inisiatif untuk segera membawa anggota keluarganya yang sakit ke puskesmas dan RS swasta terdekat, tetapi tidak paham alur sistem rujukan.

Supir ambulans desa dapat dihubungi 24 jam. Semua warga sudah mengetahui nomor telepon supir ambulans desa. Nomor tersebut ditulis di papan pengumuman dekat dengan garasi. Belum ada yang bertugas dalam mengelola warga yang membutuhkan pertolongan segera. Hanya saja informasi bisa langsung dibagikan melalui jejaring komunikasi. Tidak semua warga dan perangkat desa mengetahui nomor telepon IGD Puskesmas Cukir.

Hasil diskusi FGD telah disepakati alur komunikasi yang sederhana dan mudah dibaca oleh semua warga Desa Grogol. Pada alur tersebut juga mencantumkan peringatan tanda dan gejala awal stroke, tools F.A.S.T stroke, nomor telepon perawat, bidan, supir ambulans desa Grogol, dan IGD Puskesmas Cukir. Alur tersebut di cetak berupa banner dan diletakkan di dekat kantor Kepala Desa Grogol.

Susunan acara sesuai dengan perencanaan yang telah dibuat. Peran dan tugas sesuai dengan perencanaan. Setelah itu dilaksanakan sosialisasi dan pelatihan deteksi dini F.A.S.T stroke. Peserta mampu menyebutkan pengertian, penyebab, faktor risiko, jenis serta tanda dan gejala penyakit stroke. Peserta mampu menyebutkan dan mengulang tools F.A.S.T. stroke.

Pada saat sosialisasi dan pelatihan kader dan perangkat desa Grogol sangat antusias mencatat materi yang diberikan oleh pelaksana. Terdapat beberapa pertanyaan tentang penatalaksanaan pasien stroke dan dijawab dengan bahasa yang sederhana agar dapat dimengerti oleh peserta.

Setelah kegiatan, peserta mengisi kuesioner kepuasan kegiatan. Dari kuesioner tersebut dapat diketahui bahwa semua kader berjenis kelamin perempuan. Rata-rata usia 42,4 tahun, usia termuda 35 tahun, dan usia tertua 58 tahun. Tingkat pendidikan peserta SMP sebesar $9 \%$ dan tingkat pendidikan SMA sebesar $91 \%$. Semua kader adalah ibu rumah tangga. Hasil kuesioner kepuasan diketahui bahwa sebesar $45 \%$ menyatakan puas dengan adanya kegiatan ini. Sebesar 55 $\%$ menyatakan sangat puas. Sebanyak 3 orang perangkat desa tidak mengisi kuesioner dikarenakan ketika selesai acara menghadiri kegiatan lainnya.

Beberapa kader dan kepala desa menginginkan kegiatan ini disosialisasikan lagi di acara-acara yang ada di masyarakat seperti pengajian warga.

\section{Pembahasan}

Manajemen pra-hospital adalah tindakantindakan yang dapat diberikan pada pasien stroke baik saat masih di rumah maupun tindakan sebelum dirujuk ke rumah sakit serta 
tindakan-tindakan yang dapat dilakukan di ruang rawat darurat untuk mencegah perburukan sebelum dilakukan terapi sesuai dengan jenis patologisnya (Setyopranoto, 2010).

Pengenalan tanda dan gejala dini stroke dan upaya rujukan ke rumah sakit harus kepada masyarakat harus segera dilakukan karena keberhasilan terapi stroke sangat ditentukan oleh kecepatan tindakan pada fase akut (jendela terapi- therapeutic window). Semakin lama upaya rujukan ke rumah sakit/pusat pelayanan kesehatan terdekat atau makin panjang selang waktu antara saat serangan dengan saat pemberian terapi berarti makin buruk prognosisnya (Setyopranoto, 2010).

Konsep utama dalam penatalaksanaan stroke adalah periode emas dan "time is brain", idealnya pasien stroke sudah mendapatkan tata laksana dalam tiga jam sejak gejala pertama dikenali sehingga penatalaksanaanya harus sesegera mungkin (Antara, 2013). Waktu adalah hal yang sangat penting dalam menentukan keberhasilan tindakan pada pasien stroke akut. Namun terdapat beberapa faktor lain yang menentukan kecepatan penanganan segera di rumah sakit, misalnya jarak ke rumah sakit, kondisi lalu lintas maupun cuaca, sehingga di negara-negara maju salah satu alat transportasi utama untuk upaya rujukan ke rumah sakit adalah helikopter sebagai ambulan udara (Setyopranoto, 2010).

Pelayanan emergensi pra-hospital merupakan pelayanan yang diberikan oleh tim ambulan sebagai transportasi emergensi sebelum pasien tiba dan diterima oleh rumah sakit. Pelayanan emergensi pra-hospital membutuhkan kecepatan dan ketepatan untuk meminimalisir resiko pasien. Sehingga durasi response time menjadi indikator penting dalam pelayanan emergensi pra-hospital (Oktaviani, Yoki, Hasanbasri, 2013)
Pelayanan emergensi pra-hospital di Kota Yogyakarta dilakukan oleh Yogyakarta Emergency Services 118 (YES 118) dengan mengadopsi dua model layanan emergensi tersentralisasi (oleh ambulan PMI) dan layanan emergensi terdistribusi (oleh ambulan rumah sakit). Response time pelayanan emergensi tersentralisasi lebih cepat dibandingkan model distribusi. Model distribusi menggunakan alur komunikasi yang kompleks sehingga menambah durasi response time (Oktaviani, Yoki, Hasanbasri, 2013).

Pembentukan EMS sederhana merupakan bagian terkecil dari upaya Public Safety Center (PSC) atau Pos Pelayanan Gawat Darurat Terpadu (Pos Yan Gadar Terpadu) menjamin respon cepat dan tepat untuk menyelamatkan nyawa dan mencegah kecacatan setiap orang yang mengalami kegawatdaruratan. PSC merupakan pusat pelayanan yang menjamin kebutuhan masyarakat dalam di kabupaten/kota yang merupakan ujung tombak pelayanan untuk mendapatkan respon cepat.

Kabupaten atau kota di seluruh Indonesia sesuai Keputusan Menteri Kesehatan tersebut diwajibkan membentuk dan melaksanakan program PSC dengan menyesuaikan kapasitas dan kemampuan masing-masing daerah. Komponen penting untuk terselenggaranya program PSC ini perlu adanya sistem meliputi peraturan hukum internal, call center, alur/SOP koordinasi, kebijakan masing-masing Satuan Kerja Perangkat Daerah (SKPD), jejaring kerjasama dan hal-hal yang berkaitan dengan kebutuhan koordinasi termasuk kerjasama dengan lintas sektor (Fikriana, 2018)

Kabupaten Jombang dalam hal ini RSUD Jombang sudah melaksanakan pengenalan PSC dan penanganan kegawatdaruratan 
masyarakat awam pada tahun 2016. Sehingga diharapkan masyarakat Jombang dapat mengetahui implementasi dan keberlanjutan program PSC yang sudah dikembangkan.

Pengembangan tentang komunikasi, sumber daya, disposisi, struktur birokrasi, kebijakan, lingkungan kebijakan, dalam penanganan kegawatdaruratan terpadu, respon petugas terhadap pemohon pelayanan PSC, kecepatan, ketepatan, kecermatan, petugas dalam melaksanakan pelayanan PSC, dan respon petugas terhadap keluhan masyarakat mengenai pelayanan PSC diperlukan dalam impementasinya (Wiratma et al., 2013).

\section{Kesimpulan}

1. Kader Desa Grogol wilayah kerja Puskesmas Cukir, sudah diberikan sosialisasi dan pelatihan deteksi dini F.A.S.T. (Detection) stroke agar dapat meningkatkan pengetahuan, memberikan standar penilaian yang mudah dalam mengenali tanda dan gejala awal serangan, serta dapat meningkatkan kewaspadaan masyarakat tentang serangan stroke

2. Komunikasi dapat dilakukan melalui jejaring komunikasi yang sudah ada "Kader Grogol Nyentrik", beserta perangkat, supir ambulans, bidan, dan perawat desa. Semua informasi tentang masyarakat yang membutuhkan pertolongan segera dapat dibagikan di grup tersebut (Dispatch).

3. Desa Grogol memiliki fasilitas pelayanan mobil ambulans desa dari Pemerintah Kabupaten Jombang, yang bertujuan untuk memudahkan transportasi (Delivery) warga ke fasilitas kesehatan terdekat. Semua warga sudah memiliki contact person supir tersebut.

4. Alur komunikasi EMS sederhana di Desa Grogol melalui 3D (Detection, Dispatch, Delivery) sudah terbentuk. Dibuktikan dengan adanya banner pemasangan hasil FGD di dekat kantor Kepala Desa, diharapkan semua warga dapat mengetahui mekanisme EMS sederhana Desa Grogol.

5. Terbentuknya EMS sederhana melalui 3D ini diharapakan dapat meningkatkan manajemen pra-hospital pasien stroke, sehingga dapat menurunkan angka mortalitas dan morbiditas.

\section{Saran}

Diharapkan dapat melakukan sosialisasi tentang EMS sederhana melalui 3D (Detection, Dispatch, Delivery) dalam meningkatkan manajemen pre hospital pasien stroke di semua desa pada wilayah kerja Puskesmas Cukir.

\section{Referensi}

American Heart Association.(2013).Guidelines for the Early Management of Patients With Acute Ischemic Stroke A Guideline for Healthcare Professionals From the American Heart Association/American Stroke Association. 870 947.https://doi.org/10.1161/STR.0b013e3 $18284056 \mathrm{a}$

Antara, A., (2013). TATALAKSANA STROKE PRA RUMAH SAKIT; “ TIME IS BRAIN ." SMF Neurologi RSUD. Kabupaten Karangasem

Fikriana, R. (2018). PENGARUH SIMULASI PUBLIC SAFETY CENTER TERHADAP PENINGKATAN SELF EFFICACY KOORDINASI SISTEM PENANGGULANGAN GAWAT DARURAT TERPADU The Effect of Public Safety Center Simulation Toward Increased Self Efficacy in Integrated Emergency Service System Coordinati. Ejournal, 9, 35-42. Retrieved from http://ejournal.umm.ac.id/index.php/keper awatan/issue/view\%0APENGARUH 
Jauch, E.C., French, D. M., \& McGeorge, T. (2016). Prehospital Stroke Treatment (EMS Stabilization Protocols). Home Healthcare Now, 34(5), 259-266. https://doi.org/10.1097/NHH.0000000000 $\underline{000387}$

Oktaviani, E., Yoki S., G., Hasanbasri, M., (2013). Sentralisasi Layanan Emergensi Sebagai Upaya Peningkatan Durasi Response Time. Seminar Nasional Sistem Informasi Indonesia, 2-4. https://doi.org/10.1017/S0016756811000 $\underline{422}$.

Setyopranoto, I. (2010). Manajemen Umum stroke di Ruang Rawat Darurat. Stroke, 351-355.

Yanagida, T., Fujimoto, S., Inoue, T., \& Suzuki, S. (2014). Causes of prehospital delay in stroke patients in an urban aging society. Journal of Clinical Gerontology and Geriatrics, 5(3), 77-81. https://doi.org/10.1016/j.jcgg.2014.02.00 1

Wiratma, B., Program, M., Ilmu, S., Negara, A., Administrasi, D., Ilmu, F., ... Airlangga, U. (2013). ( Studi Tentang Responsivitas Program Public Safety Center di Kabupaten Tulungagung ), 1-7. 